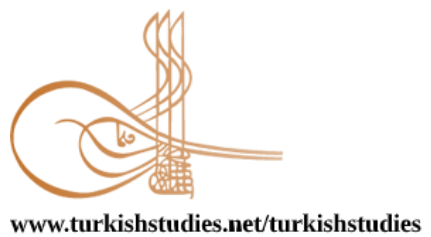

Turkish Studies

\title{
Üniversite Eğitimi Alan Öğrencilerin Korona Virüs Salgını Sürecinde Sabır Eğilimlerinin Araş̧tırılması
}

\author{
Investigation of Patience Trends in the Corona Virus Outbreak Process of University Students
}

\author{
Erol Doğan*- Osman İmamoğlu**
}

\begin{abstract}
The aim of this study is to investigate the tendency of patience of university education students during the corona virus epidemic process. The patience scale filled by 618 students studying at the university was evaluated. In statistical operations, t-test, Paired-t, one-way analysis of variance and LSD tests were used. Ondokuz May1s University Social and Humanities Ethics committee decision was taken for the study (decision dated 23.06.2020 and numbered 2020/409).
\end{abstract}

There was no statistically significant difference between the patience tendencies of the university students according to the answers given by the pre-epidemic situation by gender ( $p>0.05$ ). While scoring the answers given by considering the order of the outbreak, there was a statistically significant difference in the interpersonal patience and total patience scores between patience tendencies $(p<0.05)$. No significant difference was found in the case of long-term patience and short-term patience ( $p>0.05)$. In this study, the preepidemic patience scores were significantly higher than the patience scores calculated after the epidemic ( $p$ $<0.001)$. It was found that students' patience did not change significantly according to their watching TV and internet-related developments regarding Corona virus and their exposure to these news on social media ( $p>$ 0.05). The gender variable did not affect the patience tendency levels of university students much. It can be said that students are not affected by social media about news and information about Corona virus.

Conclusion: A statistically significant difference was found in interpersonal patience and total patience scores of university students during the epidemic process by gender. It has been determined that university students' patience tendency scores decreased due to the corona virus outbreak. It is recommended that this study be performed on students who do or do not walk, run or physical activity during the epidemic.

Structured Abstract: Introduction: The word patience refers to the state of calmness and calm in the face of situations and events that you will not like in your daily life or life. Patience is waiting for the person calmly in the face of frustration, distress and pain (Schnitker, 2012). While the person who waits calmly is described

\footnotetext{
${ }^{*}$ Dr. Öğr. Üyesi Ondokuz Mayıs Üniversitesi, Yaşar Doğu Spor Bilimleri Fakültesi, Beden Eğitimi ve Spor Bölümü

Assistant Professor, Ondokuz Mayıs Universty, Yaşar Doğu Faculty of Sport Sciences, Department of Physical Education and Sports Teaching

ORCID 0000-0001-9986-0366

eroldogan66@hotmail.com

** * Prof Dr., Ondokuz Mayıs Üniversitesi, Yaşar Doğu Spor Bilimleri Fakültesi, Beden Eğitimi ve Spor Bölümü

Prof. Dr., Ondokuz Mayıs Universty, Yaşar Doğu Faculty of Sport Sciences Department of Physical Education and Sports Teaching

ORCID 0000-0001-6671-6042

osmani55@hotmail.com

Cite as/ Atıf: Doğan, E. \& İmamoğlu, O. (2020). Üniversite eğitimi alan öğrencilerin Korona virüs salgını sürecinde sabır eğilimlerinin araştırılması. Turkish Studies, 15(4), 315-324. https://dx.doi.org/10.7827/TurkishStudies.44382

Received/Geliş: 20 June/Haziran 2020

Accepted/Kabul: 26 August/Ağustos 2020

Copyright $\mathbb{C}$ MDE, Turkey
} 
as patient, a person who displays an anxious attitude is defined as impatient (Eliüşük \& Aslan, 2017; Avşaroğlu \& Okutan, 2018). Patience is the situation where a person waits until it ends without showing anger or anxiety when faced with any loss, disease or distress. Patience occurs when the word is used instead of values such as tolerance, tolerance, anger control, persistence. Patience is a value whose emotional dimension is generally prominent (Gül \& Çeliköz, 2018).

Method: The questionnaires filled out by students with university education were evaluated. The questionnaires were filled on a voluntary basis. Ondokuz May1s University Social and Humanities Ethics committee decision was taken for the study (decision dated 23.06.2020 and numbered 2020/409).

Data collection tools: Patience Scale: The measuring tool has a three-factor structure. The 1st, 4th, 7th, 9th and 11th items of the scale are called the first sub-dimension "Interpersonal Patience" and measure the patience based on human relations. The second sub-dimension formed by the 2nd, 5th, and 8th items of the scale is called "Patience to Life's Challenges / Long-Term Patience" and measures patience against long-lasting difficulties in life. The third sub-dimension formed by the 3rd, 6th and 10th items of the scale is called "Short Term Patience / Daily Troubles" and measures the patience against daily difficulties in life. The scale expressions are listed from "Absolutely Disagree" to "I totally agree" and are in five-point Likert type. 9 of the scale expressions were prepared as positive and 2 of them as negative ( 7 and 10 items). Negative items are reversed. The highest score of the scale is 55 and the lowest score is 11 (Doğan \& Gülmez, 2014). Internal consistency coefficient of the original test; the lowest was 0.66 and the highest was 0.80 .

Statistical transactions: SPSS 23.00 package program was used in statistical operations. KolmogorovSmirnov test was performed to test whether the data was distributed normally and it was determined that the data showed normal distribution. T-test, Paired-t, unidirectional variance analysis and LSD tests were used in statistical operations.

Results: The average age of the participants in the study is 22.24 years for men and 22.30 years for women. Their height is $177.32 \mathrm{~cm}$ in men and $164.98 \mathrm{~cm}$ in women. Body weights were determined as 76.10 $\mathrm{kg}$ in men and $58.57 \mathrm{~kg}$ in women. While the ages are similar according to gender ( $>>0.05)$, there is a statistically significant difference between height and body weights ( $\mathrm{p}<0.001)$. In this study, there was no statistically significant difference between the patience tendencies of the university students according to the answers given by the pre-epidemic situation by gender $(p>0.05)$. While scoring the answers given by considering the order of the outbreak, there was a statistically significant difference between the tendency of patience and interpersonal patience and total patience score $(\mathrm{p}<0.05)$. No significant difference was found in the case of long-term patience and short-term patience ( $p>0.05)$. The gender variable did not affect the patience tendency levels of university students much. According to the answers given by university students considering their pre-epidemic status, their interpersonal patience scores were 16.73 on average, and this score decreased to 8.57 according to their answers during the epidemic. According to the answers given by considering their pre-epidemic status, long-term patience scores were 15.50 points, while this score decreased to 9.11 according to the answers they gave during the epidemic. The short-term patience before the outbreak and the short-term patience order are 8.57 and 8.77. The total patience score decreased from 35.32 to 33.39 . In this study, the preepidemic patience scores were significantly higher than the patience scores calculated after the epidemic ( $\mathrm{p}$ $<0.001)$. The epidemic process has reduced students' patience tendencies. According to this study, it was determined that the patience tendency scores of the participants decreased during the epidemic. It is thought that students' patience has decreased due to reasons such as moving away from university environments, possibly spending more time at home, threatening the health of the epidemic. Decreases in physical activity can also affect a person's mental health, which can be experienced as unpleasant feelings such as sadness, anger, frustration and / or irritability. According to this study, it was found that students' watching patience during the day and their corona virus developments on the internet did not significantly change their patience according to their follow-up hours ( $p>0.05$ ). The vast majority of students declared that they follow developments related to the epidemic between 0-2 hours. It cannot be said that they follow the developments in this regard. For this reason, watching TV and commenting on whether the patience status of the corona virus changes according to the time to follow the developments related to Corona virus on the Internet may be insufficient. In this study, the level of patience of university students according to the status of being excused about news and information about Corona virus in social media in the last week did not show a statistically significant difference ( $p>0.005)$. The number of people who state that they have been exposed frequently is 
low. It can be said that students are not affected by social media about news and information about Corona virus.

Conclusion: A statistically significant difference was found in interpersonal patience and total patience scores of university students during the epidemic process by gender. It has been determined that university students' patience tendency scores decreased due to the corona virus outbreak. It is recommended that this study be performed on students who do or do not walk, run or physical activity during the epidemic.

Keywords: Sports, Corona Virus, Patience, Student, Education.

Öz: Bu çalışmanın amacı Üniversite eğitimi alan öğrencilerin Korona virüs salgını sürecinde sabır eğilimlerinin araştırılmasıdır. Üniversite eğitimi almakta olan 618 öğrencinin doldurduğu sabır ölçeği değerlendirilmiştir. İstatistiksel işlemlerde t-testi, Paired-t, tekyönlü varyans analizi ve LSD testleri kullanılmıştır. Çalışmaya Ondokuz Mayıs Üniversitesi Sosyal ve Beşeri Bilimler Etik kurul kararı alınmıştır (23.06.2020 karar tarihli ve 2020/409 sayıli karar).

Üniversite öğrencilerinin cinsiyete göre salgın öncesi duruma ait verdikleri cevaplara göre sabır eğilimleri arasında istatistiksel olarak anlamlı bir farklılık bulunmamıştır $(\mathrm{p}>0,05)$. Salgın sırasını düşünerek verdikleri cevaplar puanlamasında sabır eğilimleri arasında Kişiler arası sabır ve toplam sabır puanında istatistiksel olarak anlamlı farklılık bulunurken $(\mathrm{p}<0,05)$. Uzun süreli sabır ve kısa süreli sabır durumunda anlamlı bir farklılık bulunmamıştır $(\mathrm{p}>0,05)$. Bu çalışmada salgın öncesi sabır puanları salgın sonrası hesaplanan sabır puanlarından anlamlı şekilde yüksektir $(p<0,001)$. Öğrencilerin gün içerisinde Televizyon seyretme ve internette Korona virüsle ilgili gelişmeleri takip saatlerine ve sosyal medyada bu haberlere maruz kalma seviyelerine göre sabır durumlarının önemli bir şekilde değişmediği bulunmuştur $(\mathrm{p}>0,05)$. Cinsiyet değişkeni üniversite öğrencilerinde sabır eğilim düzeylerini pek fazla etkilememiştir. Öğrencilerin Corona virüsü hakkında haberler ve bilgiler hakkında sosyal medyadan etkilenmediği söylenebilir.

Sonuç: Üniversite öğrencilerinin cinsiyete göre salgın sürecinde kişiler arası sabır ve toplam sabır puanında istatistiksel olarak anlamlı farklılık bulunmuştur. Üniversite öğrencilerinin korona virüs salgını nedeni ile sabır eğilimi puanlarının düştüğü tespit edilmiştir. Bu çalışmanın salgın süresince yürüyüş, koşma veya fiziksel aktivite yapan ve yapmayan öğrenciler üzerinde yapılması önerilir.

Anahtar Kelimeler: Spor, Korona virüs, Sabır, Öğrenci, Eğitim

\section{Giriş}

Birçok ülke, enfeksiyonun yayılmasını önlemek için acil önlemler uygulayarak liderlik göstermiştir. Bu bağlamda, okullar ve üniversite, anaokulları, sinemalar, müzeler, restoranlar kapatılmış, halka açık toplantılar ve etkinlikler iptal edilmiş, karantinaya alınmış, seyahat kısıtlamaları, şehirlere giriş çıkışlar ve yüksek düzeyde kontaminasyonu olan ülkelere uçuşlar iptal edilmiştir (Hamouche,2020). Bir pandemi dünya ekonomileri ve toplumlarında keskin şoklara yol açarken bireyler üzerinde olumsuz etkileri olur (MacIntyrea, 2020; Shigemura ve vd., 2020).

Sabır kelimesi insanın günlük yaşamında veya hayatında hoşuna gitmeyecek durum ve olaylar karşısında dinginlik, sakinlik durumunu ifade etmektedir. Sabır kişinin hayal kırıklığı, sıkıntı ve acılar karşısında sakin olarak beklemesidir (Schnitker, 2012). Sakince bekleyen kişi sabırlı olarak nitelendirilirken, endişeli bir tavır sergileyen bir kişi de sabırsız olarak tanımlanır (Eliüşük ve Aslan, 2017; Avşaroğlu ve Okutan, 2018). Sabır herhangi bir kayıp, hastalık ya da sıkıntı ile karşılaşıldığında kiş̧inin kızgınlık veya endişe göstermeden bitene kadar beklemesi durumudur. Sabır kelimesinin tahammül, hoşgörü, öfke kontrolü, sebat etmek gibi değerlerin yerine kullanıldığ durumlarda olmaktadır. Sabır, genellikle duygusal boyutu öne çıkan bir değerdir (Gül ve Çeliköz,2018). Sabır, yalnızca olumsuz durumlar karşısında değil, iyi şeyleri arzu ettiğimizde de başvurduğumuz bir değerdir. Kısaca yaşamımızda yaptığımız her işte, sonucun başarılı ve olumlu olmasını sağlamakta dolayısıyla bireyin mutlu olabilmesi için vazgeçilmezdir. Sabrın ne olduğu, önemi, nasıl sabredildiği, sabretmenin ve sabırsızlı̆̆ın sonuçları vb. onun bilişsel yönünü 
oluşturmakta ve sabır eğilimini ortaya çıkarmaktadır. Sabır eğilimi bireylerin, kişiler ve olaylar karşısında davranışına yön verir. Sabır, psikolojik olarak duygu ve davranış olarak iki alt gruba da ayrılabilir. Sabır duygusu, sabrın duygusal tarafını ifade etmekte ve içsel bir durum olarak görülmektedir. Sabır davranışı ise daha çok dışa dönük ve olumsuz olaylara karşı tepkiyi ifade etmektedir (Doğan ve Gülmez, 2014). Durumluk sabır, birey sabır tutumunu kazanmamış olsa da şartlar gerektirdiğinde zorunluluktan yaşanabilmektedir. Sabır davranışı tekrarlanarak sürekli sabır tutumu geliştirilebilir. Durumluk sabır, sabrın öğrenilmesi ve tutum haline gelmesi sürecinin başlangıç aşaması kabul edilebilir. Sabır bir eğilim olduğunda ve karakter gücüne dönüştügünde sürekli sabırdan söz edilebilir (Doğan,2017; Ermiş ve İmamoğlu,2020). Kayg1 ve stres bağışıklık sistemini zayıflatmaktadır ve spor ve egzersizin yarattığı ruhsal iyilik aynı zamanda bedensel sağlık için de önemlidir (Frühauf ve vd., 2020). Korona virüs süreci insanları olumsuz psikolojik durumlara götürebilir. Kişiler umutsuzluğa düşebilirler. Depresyon başta olmak üzere sosyal istenirlik, özsayg1, fiziksel sağlık ve kendine güven gibi birçok sorun ortaya çıkabilir (Yamak ve İmamoğlu,2019). Buna karşılık düzenli fiziksel aktivitenin bireyin sağlı̆̆ ve iyiliği üzerindeki olumlu etkilerini destekleyen kapsamlı araştırmalar vardır (Akyol ve İmamoğlu,2019, Aslan ve İmamoğlu,2020).

Toplumların yaşantıları ve kültürleri birbirinden çok farklı olabilir. Örneğin Asya vücut kültüründeki yaşantılar, düşünceler ve uygulamalar diğer kıtalardaki insanlardan çok farklıdır (Türkmen ve Djanuzakov,2019a; Türkmen ve Djanuzakov,2019b). Bu farkl1lıklar Korona virüs salgınından psikolojik anlamdada etkilenmeyi değiştirebilir. Bu çalışmada Türkiye de Üniversite eğitimi alan öğrencilerin Korona virüs salgını sürecinde sabır eğilimlerinin araştırılması amaçlanmıştır.

\section{Yöntem:}

Katılımc1lar: Üniversite eğitimi alan öğrencilerin tam doldurduğu anketler değerlendirmeye alınmıştır. Anketler gönüllülük esasına göre doldurulmuştur.

\section{Verilerin toplanması:}

Ondokuz Mayıs Üniversitesi Sosyal ve Beşeri Bilimler Etik kurul kararı: 23.06.2020 karar tarihli ve 2020/409 sayılı karar ile etik kurul alınmıştır. " Üniversitemiz Yaşar Doğu Spor Bilimleri Fakültesi Öğretim Üyesi Dr. Erol DOĞAN' in "Üniversitede Eğitim Alan Öğrencilerin Korona Virüs Salgını Süresince Sabır Eğilimlerinin Araştırılması” isimli araştırmaya ilişkin anket ve bilgisayar ortamında test uygulaması çalışmalarının kabulüne oy birliği ile karar verildi.

Sabır Ölçeği: Ölçme aracı üç faktörlü bir yapıya sahiptir. Ölçeğin 1., 4., 7., 9. ve 11. maddeleri birinci alt boyut-"Kişilerarası Sabır" olarak adlandırılmakta ve insan ilişkilerine dayalı sabrı ölçmektedir. Ölçeğin 2., 5., 8. maddelerinin oluşturmuş olduğu ikinci alt boyut "Hayatın Zorluklarına Sabır / Uzun Süreli Sabır" olarak adlandırılmakta ve hayattaki uzun süren zorluklara karşı sabrı ölçmektedir. Ölçeğin 3., 6. ve 10. maddelerinin oluşturmuş olduğu üçüncü alt boyut ise "Kısa Süreli Sabır/Günlük Sıkıntılar" olarak adlandırılmakta ve hayatta günlük olarak karşılaşılan sıkıntılara karşı sabrı ölçmektedir. Ölçek ifadeleri "Kesinlikle Katılmıyorum"dan "Tamamen Katılıyorum"a doğru sıralanmaktadır ve beşli likert tipindedir. Ölçek ifadelerinin 9"u olumlu, 2'si ise olumsuz (7. ve 10. Maddeler) olarak hazırlanmıştır. Olumsuz maddeler ters kodlanmaktadır. Ölçeğin en yüksek puan1 55 ve en düşük puanı ise 11'dir (Doğan ve Gülmez,2014). Orjial testin iç tutarlık katsayısı; en düşük 0,66 iken en yüksek ise 0,80 olarak hesaplanmıştır.

\section{İstatistiksel işlemler:}

İstatistiksel işlemlerde SPSS 23,00 paket programı kullanılmıştır. Verilerin normal dağılıp dağılmadığını test etmek için Kolmogorov-Smirnov testi yapılmış ve verilerin normal dağılım gösterdiği tespit edilmiştir. İstatistiksel işlemlerde t-testi, Paired-t, tekyönlü varyans analizi ve LSD testleri kullanılmıştır 


\section{Bulgular}

Tablo 1: Katılımcıların Cinsiyete Göre Yaş, Boy ve Vücut Ağırlığı Ortalamaları

\begin{tabular}{|c|c|c|c|c|c|}
\hline & Cinsiyet & $\mathrm{N}$ & Ortalama & St.sapma & t- testi \\
\hline \multirow[t]{2}{*}{ Yaş (yıl) } & Erkek & 284 & 22,24 & 6,08 & \multirow[t]{2}{*}{$-0,11$} \\
\hline & Kadın & 334 & 22,30 & 6,52 & \\
\hline \multirow[t]{2}{*}{ Boy uzunluğu (cm) } & Erkek & 284 & 177,32 & 6,39 & \multirow[t]{2}{*}{$25,55^{* *}$} \\
\hline & Kadın & 334 & 164,98 & 5,64 & \\
\hline \multirow[t]{2}{*}{ Vücut ağırlığı (kg) } & Erkek & 284 & 76,10 & 12,78 & \multirow[t]{2}{*}{$20,41 * *$} \\
\hline & Kadın & 334 & 58,57 & 8,46 & \\
\hline
\end{tabular}

Tablo 2: Cinsiyete göre salgın öncesi ve salgın sürecindeki sabır eğilimleri karşılaştırılması

\begin{tabular}{|c|c|c|c|c|c|c|}
\hline & Parametreler & Cinsiyet & $\mathrm{N}$ & Ortalama & $\begin{array}{l}\text { St. } \\
\text { Sapma }\end{array}$ & t-test \\
\hline \multirow{8}{*}{$\begin{array}{l}\text { Salgın öncesi } \\
\text { durum }\end{array}$} & \multirow{2}{*}{$\begin{array}{l}\text { Kişiler arası } \\
\text { sabir }\end{array}$} & Erkek & 284 & 16,66 & 4,13 & $-0,39$ \\
\hline & & Kadın & 334 & 16,78 & 3,67 & \\
\hline & \multirow{2}{*}{$\begin{array}{l}\text { Uzun süreli } \\
\text { sabır }\end{array}$} & Erkek & 284 & 10,12 & 2,56 & 0,87 \\
\hline & & Kadın & 334 & 9,95 & 2,38 & \\
\hline & \multirow{2}{*}{$\begin{array}{l}\text { Kısa süreli } \\
\text { sabır }\end{array}$} & Erkek & 284 & 8,60 & 1,80 & 0,40 \\
\hline & & Kadın & 334 & 8,54 & 1,96 & \\
\hline & \multirow[t]{2}{*}{ Toplam sabır } & Erkek & 284 & 35,38 & 6,31 & 0,23 \\
\hline & & Kadın & 334 & 35,27 & 5,59 & \\
\hline \multirow{8}{*}{$\begin{array}{l}\text { Salgin } \\
\text { sirasındaki } \\
\text { durum }\end{array}$} & \multirow{2}{*}{$\begin{array}{l}\text { Kişiler arası } \\
\text { sabır }\end{array}$} & Erkek & 284 & 15,94 & 4,41 & $2,48 *$ \\
\hline & & Kadın & 334 & 15,13 & 3,74 & \\
\hline & \multirow{2}{*}{$\begin{array}{l}\text { Uzun süreli } \\
\text { sabır }\end{array}$} & Erkek & 284 & 9,20 & 1,62 & 1,23 \\
\hline & & Kadın & 334 & 9,04 & 1,76 & \\
\hline & \multirow{2}{*}{$\begin{array}{l}\text { Kisa süreli } \\
\text { sabır }\end{array}$} & Erkek & 284 & 8,73 & 1,97 & $-0,47$ \\
\hline & & Kadın & 334 & 8,81 & 1,98 & \\
\hline & \multirow[t]{2}{*}{ Toplam sabır } & Erkek & 284 & 33,88 & 6,00 & $2,06^{*}$ \\
\hline & & Kadın & 334 & 32,98 & 4,90 & \\
\hline
\end{tabular}

Tablo 3: Salgın öncesi durum ve salgın sürecindeki durumda sabır eğilimlerinin karşılaştırılması

\begin{tabular}{lrrrr}
\hline & $\mathrm{n}$ & Ortalama & St. sapma & Paired-t \\
\hline Salgın öncesi kişiler arası sabır & 618 & 16,73 & 3,88 & \multirow{2}{*}{$9,36^{* *}$} \\
\hline Salgın sürecinde kişilerarası sabır & 618 & 15,50 & 4,08 & \\
\hline Salgın öncesi uzun süreli sabır & 618 & 10,03 & 2,47 & \multirow{2}{*}{$10,35^{* *}$} \\
\hline Salgın sürecinde uzun süreli sabır & 618 & 9,11 & 1,69 & \\
\hline Salgın öncesi kısa süreli sabır & 618 & 8,57 & 1,89 & \multirow{2}{*}{$-4,46^{* *}$} \\
\hline Salgın sürecinde kısa süreli sabır & 618 & 8,77 & 1,97 & \\
\hline Salgın öncesi sabır toplam puan & 618 & 35,32 & 5,93 & \multirow{2}{*}{$10,25^{* *}$} \\
\hline Salgın sürecinde sabır toplam puan & 618 & 33,39 & 5,44 & \\
\hline
\end{tabular}

$$
* * p<0,001
$$


Tablo 4: Salgın sürecinde Gün içerisinde TV seyretme ve internette Korona virüsle ilgili gelişmeleri takip saatlerine göre sabır durumlarının karşılaştırılması

\begin{tabular}{|c|c|c|c|c|c|}
\hline & & $\mathrm{N}$ & Ortalama & St.sapma & $\mathrm{F}$ \\
\hline \multirow[t]{3}{*}{ Kişiler arası sabır } & $0-2$ saat (1) & 442 & 15,47 & 4,01 & \multirow[t]{3}{*}{0,23} \\
\hline & 3-4 saat (2) & 126 & 15,71 & 3,90 & \\
\hline & 5 saat ve üzeri(3) & 50 & 15,32 & 5,12 & \\
\hline \multirow[t]{3}{*}{ Uzun süreli sabır } & $0-2$ saat (1) & 442 & 9,11 & 1,68 & \multirow[t]{3}{*}{0,99} \\
\hline & 3-4 saat $(2)$ & 126 & 9,24 & 1,63 & \\
\hline & 5 saat ve üzeri(3) & 50 & 8,84 & 1,95 & \\
\hline \multirow[t]{3}{*}{ Kısa süreli sabır } & $0-2$ saat $(1)$ & 442 & 8,75 & 1,89 & \multirow[t]{3}{*}{0,37} \\
\hline & 3-4 saat (2) & 126 & 8,78 & 2,34 & \\
\hline & 5 saat ve üzeri(3) & 50 & 9,00 & 1,64 & \\
\hline \multirow[t]{3}{*}{ Toplam sabir } & $0-2$ saat $(1)$ & 442 & 33,32 & 5,42 & \multirow[t]{3}{*}{0,72} \\
\hline & $3-4$ saat $(2)$ & 126 & 33,73 & 4,86 & \\
\hline & 5 saat ve üzeri(3) & 50 & 33,16 & 6,95 & \\
\hline
\end{tabular}

Tablo 5: Son bir haftada sosyal medyada Korona virüs hakkında haber ve bilgiye mazur kalma durumuna göre sabır durumları karşılaştırılması

\begin{tabular}{|c|c|c|c|c|c|}
\hline & & $\mathrm{N}$ & Ortalama & St.sapma & $\mathrm{F}$ \\
\hline \multirow[t]{4}{*}{ Kişiler arası sabır } & Asla+Arada bir (1) & 88 & 15,84 & 3,72 & \multirow[t]{4}{*}{1,22} \\
\hline & Bazen (2) & 96 & 15,44 & 4,43 & \\
\hline & Genellikle (3) & 252 & 15,74 & 3,81 & \\
\hline & Çok sık (4) & 182 & 15,05 & 4,39 & \\
\hline \multirow[t]{4}{*}{ Uzun süreli sabır } & Asla+Arada bir (1) & 88 & 9,43 & 1,72 & \multirow[t]{4}{*}{2,11} \\
\hline & Bazen (2) & 96 & 9,13 & 1,58 & \\
\hline & Genellikle (3) & 252 & 8,94 & 1,64 & \\
\hline & Çok sık (4) & 182 & 9,20 & 1,79 & \\
\hline \multirow[t]{4}{*}{ Kısa süreli sabır } & Asla+Arada bir (1) & 88 & 8,59 & 2,14 & \multirow[t]{4}{*}{1,92} \\
\hline & Bazen (2) & 96 & 8,85 & 1,84 & \\
\hline & Genellikle (3) & 252 & 8,97 & 1,84 & \\
\hline & Çok sık (4) & 182 & 8,55 & 2,11 & \\
\hline \multirow[t]{4}{*}{ Toplam sabır } & Asla+Arada bir (1) & 88 & 33,86 & 4,75 & \multirow[t]{4}{*}{1,11} \\
\hline & Bazen (2) & 96 & 33,41 & 5,90 & \\
\hline & Genellikle (3) & 252 & 33,64 & 5,11 & \\
\hline & Çok sık (4) & 182 & 32,80 & 5,92 & \\
\hline
\end{tabular}

\section{Tartışma ve Sonuç}

Çalışmaya katılanların yaş ortalaması erkeklerde 22,24 yıl ve kadınlarda 22,30 y1l şeklindedir. Boy uzunlukları erkelerde $177,32 \mathrm{~cm}$ ve kadınlarda $164,98 \mathrm{~cm}$ 'dir. Vücut ağırlıkları erkeklerde $76,10 \mathrm{~kg}$ ve kadınlarda 58,57 kg olarak tespit edilmiştir. Cinsiyete göre yaşlar birbirine benzer iken $(\mathrm{p}>0,05)$, boy uzunluğu ve vücut ağırlıkları arasında istatistiksel olarak anlamlı farklılık vardır $(\mathrm{p}<0,001)$.

Covid-19 salgınının etkisi sosyoekonomik tabakalar, yaş grupları, cinsiyet, kültür ve kişiliğe göre değişir ( Jeronimus,2020). Gül ve Çeliköz (2018) çalışmalarında cinsiyete göre üniversite öğrencilerinin sabır eğilim puanları arasında tüm alt boyutlarda anlamlı farklılık olduğunu bulmuşlardır. Ceylan ve vd.,(2019) çalışmalarında cinsiyete göre boksörlerin sabır eğiliminde fark bulmamıştır. Ermiş ve İmamoğlu (2019) çalışmalarında değişik fakülte öğrencilerinde cinsiyete göre kişiler arası sabır, uzun süreli sabır, kısa süreli sabır alt ölçek ve toplam sabır puanları arasında anlamlı bir farklılık bulmuştur. Çalışmaların sonuçları bu anlamda değişmektedir. Bu çalışmada Üniversite öğrencilerinin cinsiyete göre salgın öncesi duruma ait verdikleri cevaplara göre sabır eğilimleri arasında istatistiksel olarak anlamlı bir farklılık bulunmamıştır ( $\mathrm{p}>0,05)$. Salgın sırasını düşünerek verdikleri cevaplar puanlamasında sabır eğilimleri arasında kişiler arası sabır ve toplam 
sabır puanında istatistiksel olarak anlamlı farklılık bulunurken $(\mathrm{p}<0,05)$. Uzun süreli sabır ve kısa süreli sabır durumunda anlamlı bir farklılık bulunmamıştır $(\mathrm{p}>0,05)$. Cinsiyet değişkeni üniversite öğrencilerinde sabır eğilim düzeylerini pek fazla etkilememiştir.

Doğan (2017) çalışmasında sabır düzeyi yüksek olan grubun psikolojik iyi olma düzeyinin, sabır düzeyi düşük olan gruba göre daha yüksek olduğunu belirtmiştir. Sabır ölçeğinin en yüksek puanı 55 ve en düşük puanı ise 11'dir (Doğan ve Gülmez,2014). Bu çalışmada Üniversite öğrencilerinin salgın öncesi durumlarını düşünerek verdikleri cevaplara göre kişiler arası sabır puanları ortalama 16,73 puan iken salgın sırasındaki verdikleri cevaplara göre bu puan 8,57'ye düşmüștür. Yine salgın öncesi durumlarını düşünerek verdikleri cevaplara göre uzun süreli sabır puanları ortalama 15,50 puan iken salgın sırasındaki verdikleri cevaplara göre bu puan 9,11'e düşmüştür. Salgın öncesi kısa süreli sabır ve salgın sırası kısa süreli sabır değerleri 8,57 ve 8,77'dir. Toplam sabır puanı ise 35,32 puandan 33,39 puana düşmüştür. Bu çalışmada salgın öncesi sabır puanları salgın sonrası hesaplanan sabır puanlarından anlamlı şekilde yüksektir $(p<0,001)$. Salgın süreci öğrencilerin sabır eğilimlerini azaltmıştır.

Bu çalışmaya göre katılımcıların sabır eğilimi puanlarının salgın sırasında düştüğü tespit edilmiştir. Öğrencilerin üniversite ortamlarından uzaklaşma, muhtemelen de evde daha fazla zaman geçirmeleri, salgının sağlıklarını tehdit eden etkisi gibi nedenlerle sabırlarının düştüğü düşünülmektedir. Fiziksel aktivitedeki azalmalar kişinin üzüntü, öfke, hayal kırıklı̆̆ı ve / veya sinirlilik gibi hoş olmayan duygular olarak deneyimlenebilen zihinsel sağlığını da etkileyebilir. Karantinanın psikolojik etkisi ile hastalık salgınlarının yaşanmasının diğerleri arasında travma sonrası stres, depresyon ve / veya karışıklık semptomlarını tetikleyebileceği belirtilmiştir (Brooks ve vd.,2020; Lippi ve vd.,2020; Sanchis ve vd.,2015). Dikkatin başka şeylere yöneltilmesi psikolojik rahatlama sağlayabilir (Aksoy ve vd.,2020).

Sabır düzeyi yüksek olan bireylerin aynı zamanda bağımsız, özgür irade sahibi, davranışlarını düzenleyebilen ve sosyal baskılara direnen ve mücadele eden, kendi kontrolünün dışındaki sebepler veya kurumlar tarafindan yönetilmeye izin vermeyen, kendi eylem ve düşüncelerine inanan bireyler oldukları belirtilmiştir. Yine sabır düzeyi yüksek bireylerin aynı zamanda kendi istek ve ihtiyaçları doğrultusunda çevrelerindeki yaşamı etkili bir şekilde yönlendirebilen, olaylar karşısında pasif bir bekleyiş içerisinde olmayan bireyler olduklan ifade edilmiştir (Ceylan ve vd.2017). Öğrencilerin sabır düzeylerinin düşmesi öğrencilerin yaşamlarını etkili bir şekilde yönlendirmelerinde olumsuz durum oluşturur. Zaten korona virüs salgını süresince bu durum pek mümkün de gözükmemektedir. İnsanlar ve toplumlar farklı tehdit ve kontrol yoğunlukları ve endişe ve hayal kırıklığı gibi duygular yaşadılar ve farklı davrandılar. Politikalar ve vatandaşların uyumu, sosyal izolasyon ve uzun süreli sosyal etki azaltma önlemleri sırasında enfeksiyon riskini, ölümleri ve dayanıklılıklarını etkilemiştir (Jeronimus, 2020).

İnternet, telefonlar ve televizyon aracılığıyla bedensel aktiviteyi teşvik etmeye ve sunmaya odaklanılmıştır. Sağlık ve egzersiz videolarının kullanımı, bu kritik dönemde bedensel ve ruhsal sağlı̆̆ı sürdürmenin diğer geçerli yolları olarak görülür (Chen ve vd.,2020). Sosyal medya, COVID19 hakkında güncellenmiş bilgi sağlayan ana kanallardan biridir. Her ne kadar uzaktaki akrabalarıyla karantinaya alınan bireylerin iletişimini kolaylaştırmakta önemli bir rol oynayabilir. Sosyal medya her zaman pandemi ile ilgili güncellemeler için güvenilir bir bilgi kaynağı değildir. Aslında, yanlış bilgi aşırı yüklenmesine yol açan söylentileri veya yanlış bilgileri yayabilir, bu da birçok birey arasında asılsız korkular yaratır ( Bao ve vd.,2020; Bontcheva ve vd.,2013; Brooks ve vd.,2020). Gao ve vd. (2020), Wuhan, Çin'deki COVID-19 salgını sırasında sık sık sosyal medyaya maruz kalma ile pozitif ilişkili olan yüksek zihinsel sağlık sorunları (depresyon ve kaygı veya her ikisinin bir kombinasyonu) olduğunu göstermiştir. Bu çalışmaya göre öğrencilerin gün içerisinde TV seyretme ve internette Korona virüsle ilgili gelişmeleri takip saatlerine göre sabır durumlarının önemli bir şekilde değişmediği bulunmuştur ( $>>0,05)$. Öğrencilerin büyük çoğunluğu 0-2 saat arası salgınla 
ilgili gelişmeleri takip ettiklerini beyan etmişlerdir. Çok fazla bu konuda gelişmeleri takip ettikleri söylenemez. Bu nedenle TV seyretme ve internette Korona virüsle ilgili gelişmeleri takip saatlerine göre sabır durumlarının değişip değişmediği üzerine yorum yapmak yetersiz kalabilir.

Bu çalışmada Üniversite öğrencilerinin son bir haftada sosyal medyada Korona virüs hakkında haber ve bilgiye mazur kalma durumuna göre sabır durumları istatistiksel olarak önemli bir farklılık göstermemiştir $(p>0,005)$. Zaten çok sik maruz kaldıklarını belirtenlerin sayısı düşüktür. Öğrencilerin Korona virüs ile ilgili haber ve bilgiler konusunda sosyal medyadan etkilenmedikleri söylenebilir. Yamaner ve vd., (2020) tarafından yapılan bir çalışmada spor Eğitimi alan öğrencilerin Optimal performans duygu durumunun iyi olduğu belirtilmiştir. Performans durumları iyi olan öğrenciler diş etkenlerden etkilenmemişlerdir.

Sonuç: Üniversite öğrencilerinin cinsiyete göre salgın öncesi duruma ait verdikleri cevaplara göre sabır eğilimleri arasında istatistiksel olarak anlamlı bir farklılık bulunmazken Salgın sırasını düşünerek verdikleri cevaplara göre kişiler arası sabır ve toplam sabır puanında istatistiksel olarak anlamlı farklılık bulunmuştur. Üniversite öğrencilerinin korona virüs salgını nedeni ile sabır eğilimi puanlarının düştügü tespit edilmiştir. Bu çalışmanın salgın süresince yürüyüş, koşma veya fiziksel aktivite yapan ve yapmayan öğrenciler üzerinde yapılması önerilir.

\section{Kaynakça}

Aksoy, Y. \& Aslan, H. \& İmamoğlu, O. (2020). Comparison of attention levels according to sport status and age category in students. Electronic Turkish Studies, 15(3), 1473-1483. https://dx.doi.org/10.29228/TurkishStudies.41719

Akyol, P., \& İmamoğlu, O . (2019). The effect of pilates exercises on quality of life in sedentary females. Turkish Studies- Social Sciences, 14(3),238-247. https://doi.org/10.29228/turkishstudies.22544

Aslan H., \& İmamoğlu O. (2020). Investigation of leisure strategies of sports educated students. Asian Journal of Education and Training, 6(3),468-473. https://doi.org/10.20448/journal.522.2020.63.468.473

Avşaroğlu, S., \& Okutan, H. (2018). Zihin engelli çocuğu olan ailelerin yaşam doyumları, iyimserlik ve psikolojik belirti düzeylerinin incelenmesi. Manas Sosyal Araştırmalar Dergisi. 7(1), 59-76. https://doi.org/10.21560/spcd.v19i46288.453941

Bao, Y., Sun, Y., Meng, S, et al. (2020). 2019-nCoV epidemic: address mental health care to empower society. Lancet. 395(10224): e37-e38. https://doi.org/10.1016/s01406736(20)30309-3

Bontcheva, K., Gorrell, G., \& Wessels, B. (2013). Social media and information overload: Survey results. arXiv preprint arXiv:1306.0813.

Brooks, S.K., Webster, R.K., Smith, L.E., et al. (2020). The psychological impact of quarantine and how to reduce it: rapid review of the evidence. Lancet. 395(10227): 912-920. https://doi.org/10.1016/s0140-6736(20)30460-8

Bülbül, A.E., \& Arslan, C. (2017) Investigation of patience tendency levels in terms of selfdetermination, self-compassion and personality features, Universal Journal of Educational Research, 5(9), 1632-1645, 2017. https://doi.org/10.13189/ujer.2017.050921

Ceylan, L., Çebi, M., İmamoğlu, O., \& Eliöz, M. (2019). Investigation of patience trends according to being a competitive boxer, 5th International Eurasian Congress on 'Natural Nutrition, Healthy Life \& Sport', Proceedings, I:1880-1885 
Chen, P., Mao, L., Nassis, G. P., Harmer, P., Ainsworth, B. E., \& Li, F. (2020). Coronavirus disease (COVID-19): The need to maintain regular physical activity while taking precautions. Journal of sport and health science, 9(2), 103-104. https://doi.org/10.1016/j.jshs.2020.02.001

Ermiş, E., \& İmamoğlu, O. (2019). Analysis of patience predisposition of students in different faculties. International Journal of Society Researches,13(19):263-280

Frühauf, A., Schnitzer, M., Schobersberger, W., Weiss, G., \& Kopp, M. (2020). Jogging, nordic walking and going for a walk-interdisciplinary recommendations to keep people physically active in times of the covid-19 lockdown in Tyrol. Austria. Current Issues in Sport Science, 4:100.http://www.ciss-journal.org/Vol. 5 I DOI 10.15203/CISS_2020.100

Doğan, M., \& Gülmez, Ç. (2014). Sabır ölçeğinin Türkçeye uyarlanması: Geçerlik ve güvenirlik çalışması. Atatürk Üniversitesi Ilahiyat Fakültesi Dergisi, 42, 263-279. https://doi.org/10.24315/trkefd.364039

Doğan, M. (2017). Karakter gücü olarak sabır ve psikolojik iyi oluş ilişkisi. The Journal of Happiness \& Well-Being, 5(1), 134-153

Gao, J., Zheng, P., Jia, Y., et al. (2020). Mental health problems and social media exposure during COVID-19 Outbreak. Available at SSRN 3541120. https://doi.org/10.2139/ssrn.3541120

Gül, Y.E., \& Çeliköz, N. (2018). Üniversite öğrencilerinin sabır eğilim düzeylerinin incelenmesi. MANAS Sosyal Araştırmalar Dergisi, Cilt 7, sayı 3, sh:77-87. https://doi.org/10.33206/mjss.498767

Hamouche, S. (2020). COVID-19 and employees' mental health: stressors, moderators and agenda for organizational actions. Emerald Open Research, 2:15. https://doi.org/10.35241/emeraldopenres.13550.1

Jeronimus, B.F. (2020). Personality and the Coronavirus Covid-19 Pandemic. University of Groningen Press.1-98.

Lippi, G., Henry, M.B., \& Gomar, F.S. (2020) Physical inactivity and cardiovascular disease at the time of coronavirus disease (COVID-2019). European Journal of Preventive Cardiology, 27(9), 906-908. https://doi.org/10.1177/2047487320916823.

Macintyrea, C.R. (2020). On a knife's edge of a COVID-19 pandemic: is containment still possible? Public Health Res Pract. 30. https://doi.org/10.17061/phrp3012000

Schnitker, S.A. (2012) An examination of patience and well-being. The Journal of Positive Psychology, 7(4), 263-280.

Shigemura, J., Ursano, R.J., Morganstein, J.C., et al.(2020). Public responses to the novel 2019 coronavirus (2019-nCoV) in Japan: mental health consequences and target populations. Psychiatry Clin Neurosci. 74(4): 281-282. https://doi.org/10.1111/pcn.12988

Türkmen, M., \& Dzanuzakov, K. (2019a). An old horse sports in central Asian Turkish communities: Ukuruk Salmaktyy- Quriks- Emdik Uredish. Turkish Studies, 14(7), 4059-4070. Skopje/MACEDONIA-Ankara/TURKEY. https://doi.org/10.29228/turkishstudies.30291

Türkmen, M., \& Dzanuzakov, K. (2019b). Cultural Pedagogy of traditional wrestling of Turkish people. Turkish Studies, 14(6), 3525-3533, Skopje/MACEDONIA-Ankara/TURKEY. https://doi.org/10.29228/turkishstudies.30291 
Yamak, B., \& İmamoğlu O. (2019). The beck hopelessness level according to behavior change stages in University Ondokuz Mayis Students. Turkish Studies Educational Sciences, 14(3),937947, https://doi.org/10.29228/turkishstudies.22941

Yamaner, F., Çıplak E., \& İmamoğlu O. (2020). Investigation of optimal performance emotional status in sports students,Turkish Studies, 15(2), 1515-1522. https://dx.doi.org/10.29228/TurkishStudies.41771 